\title{
Strategi pengaktifan kelompok bina keluarga balita pada kampung keluarga berencana.
}

\author{
Eddy Munawar ${ }^{1 *}$, Gema Novi Renggina ${ }^{2}$ \\ ${ }^{1}$ Badan Kependudukan Keluarga Berencana Provinsi Aceh, Indonesia, email: eddymala2009@gmail.com \\ ${ }^{2}$ Badan Kependudukan Keluarga Berencana Provinsi Aceh, Indonesia, email: gemanovirenggina86@gmail.com \\ ${ }^{*}$ Koresponden penulis
}

\section{Info Artikel}

Diajukan: 23 Jun 2020

Diterima: 21 Okt 2020

Diterbitkan: 17 Nov 2020

Keywords:

village family planning;

toddler family development

\section{Kata Kunci:}

kampung keluarga

berencana; bina keluarga

balita

\section{Lisensi:}

cc-by-sa

\begin{abstract}
Family Planning Village (KB) was one of the flagship programs of the Indonesian National Population and Family Planning Agency (BKKBN). IT aimed to synergize the Concept of Family Empowerment Development, Population and Family Planning (Bangga Kencana) in the village sphere. That could improve the utilization of Family Planning services can be accessed by people living in remote villages from family planning service centres and as an effort by BKKBN to create a prosperous and quality family. One of Bangga Kencana mandatory programs in $K b$ Village was the Toddler Family Development Program (BKB). This community empowerment activity was carried out to activate the BKB group by conducting counselling, coaching, monitoring, and field assistance. From the assessment results, after the training was carried out. It appeared that the cadres of BKB Group did coach public dissemination better. They were proven from the effects of Pre-Test, and Post-Trial Cadre Supervisor $B K B$ where the initial pre-test score averaged $65.5 \%$, after conducting evaluation and education then done Post Test, where the average weight increased to $84.76 \%$. Then there was the recognition of the community based on the results of in-depth interviews that there is an increase in public awareness to participate in the active group of $B K B$ and increase the participation of citizens in every BKB Group coaching activity in Lhambuk Village.
\end{abstract}

\begin{abstract}
Abstrak
Kampung Keluarga Berencana (KB) merupakan salah satu program unggulan dari BKKBN, yang bertujuan untuk mencoba mensinergikan Konsep Pembangunan Pemberdayaan Keluarga, Kependudukan dan Keluarga Berencana (Banggakencana) di lingkup desa, sehingga pemanfaatan pelayanan Keluarga Berencana bisa diakses oleh masyarakat yang tinggal di pedesaaan yang jauh dari pusat-pusat pelayanan keluarga berencana sebagai upaya BKKBN mewujudkankan keluarga sejahtera dan berkualitas. Salah satu program Banggakencana yang wajib ada pada Kampung KB adalah kegiatan Bina Keluarga Balita (BKB). Kegiatan Pemberdayaan masyarakat ini dilakukan untuk mengaktifkan Kelompok BKB dengan cara melakukan penyuluhan, pembinaan, monitoring dan pendampingan lapangan. Dari hasil penilaian setelah kegiatan dilakukan, terlihat semakin bagusnya kader pembina Kelompok BKB Melakukan Sosialisasi kepada masyarakat. hal ini tampak dari hasil Pre-test dan Post-Test terhadap kader Pembina BKB dimana semula nilai Pre-test rata-rata $65,5 \%$, setelah dilakukan penbinaan dan edukasi lalu dilaksanakan Post-Test, dimana nilai rata-ratanya
\end{abstract}


meningkat menjadi 84,76\%. Kemudian adanya pengakuan masyarakat berdasarkan hasil wawancara mendalam bahwa adanya peningkatan kesadaran masyarakat untuk turut serta dalam mengaktifan kelompok BKB serta peningkatan partisipasi warga dalam setiap kegiatan pembinaan Kelompok BKB Desa Lhambuk.

\section{PENDAHULUAN}

Kampung Keluarga Berencana merupakan salah satu program unggulan dari Badan Kependudukan Keluarga Berencana Nasional (BKKBN). Konsepnya dilatar belakangi untuk memajukan dan mengairahkan kembali program KB untuk merangkul masyarakat dengan scope yang lebih luas. Program ini memiliki format mencoba untuk memadukan dan mensinergikan Konsep Pembangunan Pemberdayaan Keluarga, Kependudukan dan Keluarga Berencana (Banggakencana) pada lingkup desa, sehingga pemanfaatan pelayanan Keluarga Berencana bisa diakses oleh masyarakat yang tinggal di pedesaaan yang jauh dari pusat-pusat pelayanan keluarga berencana sebagai upaya BKKBN mewujudkankan keluarga sejahtera dan berkualitas (Sanda, 2020; BKKBN, 2015).

Menurut Mardiyono (2017) konsep Kampung KB adalah model minimalis dari implementasi program keluarga berencana secara sistematis dan komprehensif pada level desa/kelurahan/dusun/RW. Konsep ini merupakan program keluarga berencana yang diintegrasikan dengan program pembangunan lainnya seperti pendidikan, kesehatan, ekonomi, infrastruktur dan program pembangunan lainnya. Kampung KB dikonsepkan sebagai upaya pemberdayaan masyarakat terhadap pengelolaan program KB. Kegiatannya dikelola berdasarkan prinsip dari, oleh, dan untuk masyarakat itu sendiri. Tujuan akhirnya tentu pembangunan masyarakat. Pemerintah hanya menstimulasi dan melakukan pendampingan, selebihnya menjadi tanggungjawab komunitas (Yunas \& Nailufar, 2019).

Desa Lhambuk merupakan salah satu desa di kecamatan Ulee Kareng Kota Banda Aceh dimana desa ini sendiri memiliki wilayah sebesar 108,4 Ha serta memiliki jumlah penduduk yang paling banyak yaitu 5508 jiwa atau $20,81 \%$ dari total seluruh penduduk Kecamatan Ulee Kareng. Pekerjaan utama penduduk desa ini adalah swasta, lalu PNS/TNI/Polri serta pedagang dan petani (Badan Pusat Statistik Kota Banda Aceh, 2019). Desa ini ditunjuk oleh sebagai Kampung KB untuk wilayah Kecamatan Ulee Kareng.

Salah satu program Banggakencana yang wajib berjalan pada Kampung KB adalah kegiatan Bina Keluarga Balita (BKB). Hal ini berdasarkan Peraturan Kepala BKKBN No. 12 Tahun 2018 tentang pengelolaan Bina Keluarga Balita Holistik Integratif (BKB HI). Program ini adalah mengelola pembinaan tumbuh kembang anak melalui pola asuh yang benar berdasarkan kelompok umur antara 3-6 Tahun (Balita). Pelaksanan Kegiatan tersebut dikelola oleh kader keluarga berencana yang berada pada tingkat desa (Putri et al., 2020).

Bina Keluarga Balita BKB adalah upaya peningkatan pengetahuan, keterampilan dan kesadaran ibu serta anggota keluarga lain dalam membina tumbuh kembang balitanya melalui rangsangan fisik, motorik, kecerdasan, 
sosial, emosional serta moral yang berlangsung dalam proses interaksi antara ibu/anggota keluarga lainnya dengan anak balita. Tujuan dari pembentukan Bina Keluarga Balita itu sendiri adalah meningkat kualitas tumbuh kembang anak sebagai generasi penerus suatu bangsa melalui peranan orang tua, agar tercapai masa depan bangsa yang baik (Setianingrum et al., 2017).

Secara teknis pembinaan program Bina Keluarga Balita (BKB) di tangani langsung oleh kader Keluarga Berencana yang berasal dari kampung itu sendiri dan dibantu oleh penyuluh keluarga berencana (PKB) Kecamatan. Kader yang berfungsi sebagai ujung tombak program diharapkan mampu memberikan sosialisasi program, penyuluhan BKB agar bertambahnya pengetahuan dan pendidikan serta memotivasi orang tua untuk meningkatkan pola asuh anak sehingga tumbuh kembang dengan baik. Hal ini sejalan dengan Penelitian dari Maryam (2017), yang mengatakan bahwa faktor pendidikan dan sosialisasi berdampak positif terhadap peningkatan kualitas pengasuhan terhadap anak.

Berdasarkan pengamatan di Kampung Lhambuk, ada beberapa permasalahan yang terlihat dilapangan terkait dengan Kegiatan BKB, yaitu Kepengurusan kader yang tidak aktif dalam menjalankan kegiatan BKB karena kebanyakan dari mereka banyak bekerja ditempat lain sehingga sosialisasi terhadap ibu-ibu tidak berjalan sesuai standar operasional yang ditetapkan sehingga tingkat pengetahuan ibu yang memiliki balita masih sangat rendah didesa tersebut, lalu Rendahnya dukungan dan partisipasi dari tokoh masyarakat mengakibatkan program tersebut seperti ada dan tiada karena dianggap bukan merupakan program prioritas.

Dari permasalahan tersebut, kami mencoba melakukan pembinaan terhadap Kelompok BKB Desa Lhambhuk Kecamatan Ulee Kareng dengan tujuan kelompok pembinaan tersebut bisa aktif kembali melakukan sosialisasi guna mendukung peningkatan kualitas Sumber daya manusia melalui pola asuh orang tua yang tepat guna.

\section{METODE PELAKSANAAN}

Guna mencapai tujuan dari pembinaan ini, maka dilakukan beberapa tahapan pelaksanaan kegiatan pembinaan, melalui koordinasi dan implementasi kegiatan dilapangan. yaitu:

\section{Koordinasi Internal}

Tujuannya adalah mengintegrasikan dan menyatukan visi pembinaan terhadap kelompok Bina Keluarga Balita (BKB) sehingga tercapai kesepakatan bersama guna mencapai tujuan akhir yaitu aktifnya kembali BKB Kampung Lhambhuk Kecamatan Ulee Kareng.

\section{Koordinasi dengan tokoh-tokoh Desa}

Tujuannya untuk meminta dukungan serta partisipasi aktif dari pihak pemerintahan Desa Lhambuk, Tokoh Agama (Ulama Desa), Tokoh Masyarakat, Tokoh Adat dan ibu-ibu PKK sebagai sasaran utama. Agar pengaktifan kembali BKB bisa berjalan lancar sesuai rencana serta pemanfaatan program dapat dirasakan langsung oleh masyarakat. 


\section{Pelaksanaan Kegiatan}

a. Sosialisasi program Bina Keluarga Balita (BKB) Tingkat Desa Sosialisasi ini bertujuan untuk memperkenallan program Bina Keluarga Balita (BKB) kepada kepala desa Lhambuk, Tokoh Agama (Ulama Desa), Tokoh Masyarakat, Tokoh Adat dan ibu-ibu PKK. Pada saat sosialisasi Tim dibantu oleh PKB Kecamatan Ulee Kareng dan Kader KB desa.

b. Mengidentifikasi pengurus serta kader BKB Bersama PKB Kecamatan Ulee Kareng, Kader KB desa dan Ketua Tim penggerak PKK desa Lhambuk.

Tujuan dari kegiatan ini adalah mengidentifikasi keaktifan pengurus dan kader BKB serta melakukan perubahan kepengurusan kelompok Bina Keluarga Balita desa Lhambuk Kecamatan Ulee Kareng.

c. Melakukan perekrutan kader baru dan penyusunan pengurus BKB Bersama PKB Kecamatan Ulee Kareng, Kader KB desa dan Ketua Tim penggerak PKK desa Lhambuk.

Tujuan dari kegiatan ini adalah melakukan perekrutan kembali kader BKB dan mengelompok kader berdasarkan umur balita serta melakukan perubahan kepengurusan kelompok Bina Keluarga Balita desa Lhambuk Kecamatan Ulee Kareng melalui Surat Keputusan (SK) Pemerintah Desa.

d. Pelatihan dan pembinaan

Tujuan dari kegiatan ini adalah memberikan pembekalan kepada kader-kader yang baru direkrut serta berdiskusi kepada mereka kendala apa saja yang dihadapi dalam rangka melakukan pembinaan dan pembelajaran terhadap para orang tua bali di desa tersebut sehingga dicarikan solusinya.

\section{HASIL DAN PEMBAHASAN}

Hasil yang di capai dari program pembinaan guna pengaktifan kembali Kelompok Kegiatan (Poktan) Bina Keluarga Balita pada kampung KB Desa Lhambuk Kecamatan ulee Kareng yang di kelompokkan berdasar tahapan kegiatan dan pengolahan, terlihat bahwa kepengurusan kader yang tidak aktif menjadi pemicu tumpang tindih kewenangan kader membina pada masingmasing kelompok umur. Tidak adanya kejelasan status terkait kader yang tidak aktif. Kader tidak berinofasi dalam memberikan penyuluhan kepada ibuibu dan Alat Permainan Edukasi yang terbatas. Setelah penulis menyelesaikan tahapan kegiatan guna mengaktifkan kembali kader Bina Keluarga Balita (BKB), terdapat perubahan pemahaman dari mereka. Dimana pada mulanya ada kader yang sudah mengundurkan diri, setelah diberi pemahaman tentang program, kembali berminat untuk masuk dan bergabung kembali ke kelompok serta mulai aktif lagi menjadi anggota Kelompok kader Bina Keluarga Balita. Hal ini selaras dengan hasil penelitian yang dilakukan oleh Putri et al. (2020) yang menunjukkan bahwa seluruh kader BKB berperan aktif dalam kegiatan BKB, namun terdapat banyak kegiatan yang belum maksimal bahkan belum terlaksana dimana hanya kegiatan inti yang sudah 
terlaksana yang disebabkan terhambatnya terbatasnya jumlah kader BKB. Berikut ini adalah foto-foto kegiatan yang telah dilaksanakan.

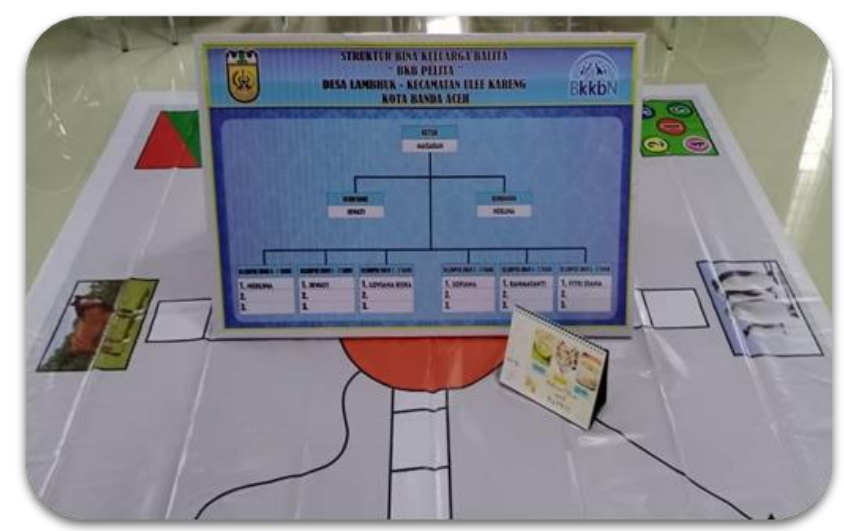

Gambar 1. Bagan struktur, alat media penyuluhan MPASI serta produk alat permainan Edukasi (APE) BKB Desa Lhambuk

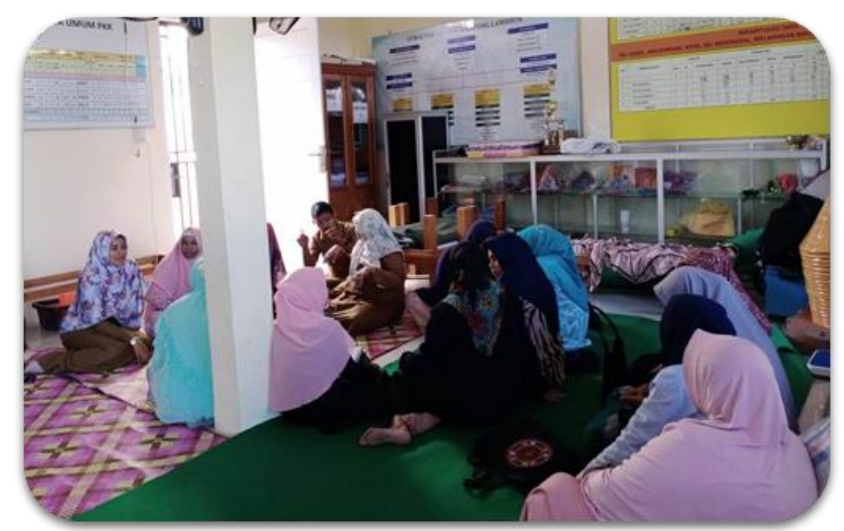

Gambar 2. Proses Konseling terhadap warga desa Lhambuk

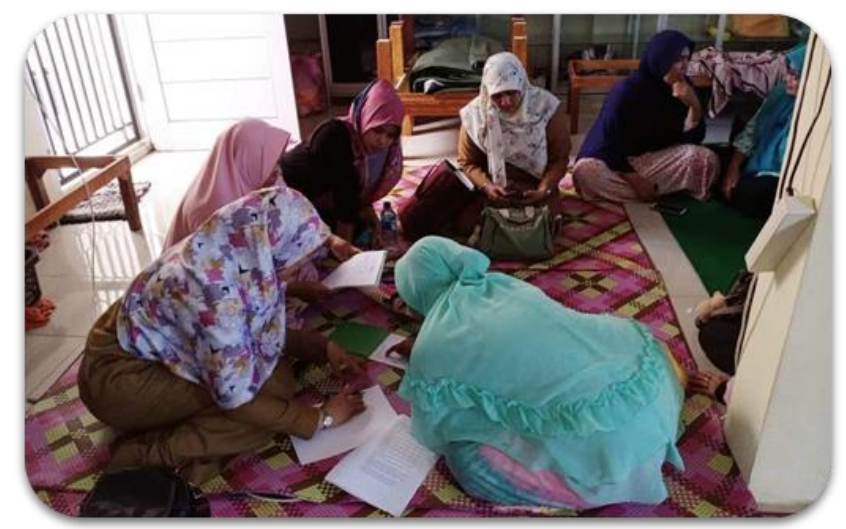

Gambar 3. Melakukan Sarasehan dan Praktek terhadap Kelompok BKB desa Lhambuk 


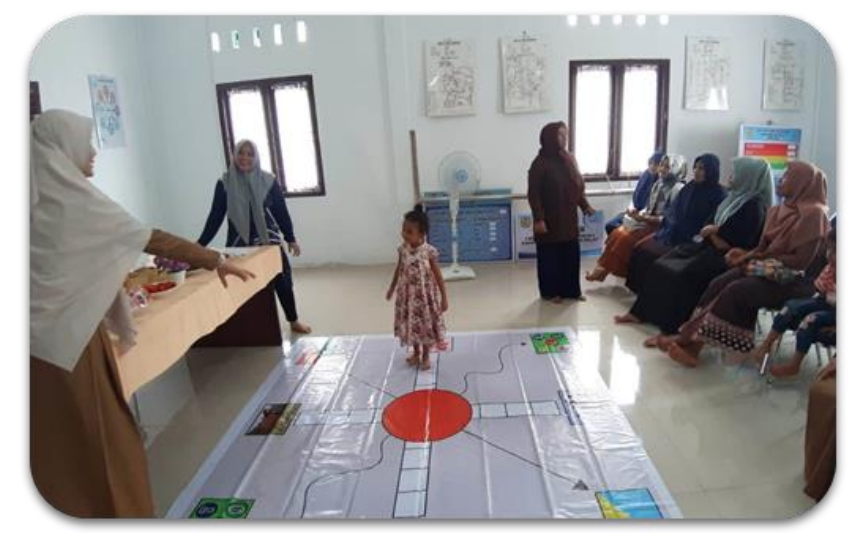

Gambar 4. Melakukan Sarasehan dan Praktek terhadap Kelompok BKB desa Lhambuk

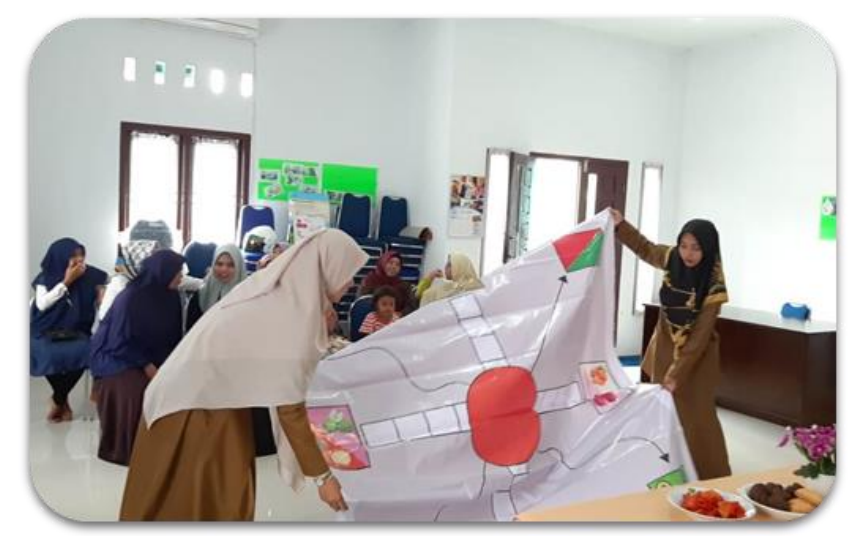

Gambar 5. Melakukan Sarasehan dan Praktek terhadap Kelompok BKB desa Lhambuk

Selanjutnya adalah hasil yang dicapai dari program pengabdian masyarakat Desa Lhambhuk Kecamatan ulee Kareng Kota Banda Aceh berdasarkan tahapan serta kegiatan yang dilakukan adalah sebagai berikut:

1. Di awali dengan melakukan Konsultasi dan Koordinasi ke Bidang Keluarga Sejahtera (KS), kegiatan tambahan ini dianggap perlu dilakukan untuk mendapatkan arahan atau petunjuk terkait apakah Bina Keluarga Balita (BKB) itu sendiri, dan petunjuk teknis kegiatan (BKB) secara menyeluruh. Kegiatan tersebut sangat membantu dalam melanjutkan tahapan kegiatan lainnya. Kemudian melakukan koordinasi dengan tokohtokoh desa guna mensinergikan persepsi dan keinginan kedua belah pihak sehingga tujuan yang akan dilaksakan akan tercapai. Hal ini selaras dengan penelitian yang dilakukan oleh Lantemona et al. (2017) yang hasil penelitian menunjukkan bahwa camat dalam melaksanakan koordinasi dalam mengupayakan peningkatan kesejahteraan masyarakat melalui pemberdayaan harus mengupayakan dan memperhatikan setiap kebutuhan yang ada di dalam masyrakat sehingga bantuan yang di salurkan memenuhi target yang telah ditentukan. 
2. Pembuatan Papan Struktur kader BKB. Ini adalah salah satu bagian yang tak terpisahkan dari kegiatan pengukuhan anggota baru Kader Kelompok Bina Keluarga Balita. Hal ini dianggap perlu sebagai perwujudan rasa bangga juga untuk memperkuat kelompok BKB untuk menumbuhkan rasa tanggung jawab kader terhadap kewajiban yang seharusnya dijalankan dan agar tidak adanya tumpang tindih kepengurusan pada kelompok umur Balita. Dengan adanya koordinasi yang baik antar kader, maka akan meningkatkan kualitas pekerjaan serta tanggung jawab akan pekerjaan tersebut (Fu et al., 2019).

3. Pembuatan alat atau media penyuluhan untuk kader yang berbentuk timbal balik yang berguna mempermudah kader melakukan pembinaan dan sosialisasi kepada masyarakat. Media penyuluhan ini menerangkan tentang produk-produk Makanan Pendamping ASI (MPASI) kepada ibuibu yang mempunyai balita. Hal ini sesuai dengan hasil penelitian yang dilakukan oleh lqmy et al. (2019) yang mengatakan bahwa dengan metode penyuluhan menggunakan lembar balik akan memiliki pengaruh yang penting pada perubahan pengetahuan ibu sebelum di edukasi dan setelah diajarkan menggunakan lembar-balik.

4. Pembuatan konsep produk Alat Permainan Edukasi (APE) bagi balita dimana Permainan ini di rancang berdasarkan pola dan gaya main anak pada usia dini. Permainan ini memadukan konsep dari menari serta permainan tradisional engklek dan ular tangga. Permainan ini dirancang agar mempermudah kader melakukan pembinaan dan mensosialisasikan kepada orang tua balita didesa tersebut bagaimana caranya dapat meningkatkan motorik kasar anak, melatih keseimbangan tubuh anak sehingga membuat anak dapat berfikir responsif serta untuk melatih anak untuk dapat bekerjasama dengan temannya sehingga diharapkan bisa membentuk kestabilan emosi anak. Permainan ini dapat dimainkan oleh anak usia 3 Tahun ke atas.

5. Melakukan kegiatan Sarasehan dan praktek dengan PPKBD dan Sub PPKBD, serta para kelompok kader BKB. Pembinaan ini dilakukan oleh penyuluh keluarga berencana. Rutinitas ini dilakukan guna menambah wawasan dan pengetahuan bagi kader, sehingga saat melakukan penyuluhan kepada ibu-ibu desa ada hal-hal baru yang disampaikan serta bisa mengajak ibi-ibu yang mempunyai balita didesa tersebut untuk berpartisipasi aktif dalam kegiatan Bina Keluarga Balita (BKB).

Ketika suatu program dibuat, tentu perlu adanya evaluasi sebagai instrumen pengukur tingkat keberhasilan pelaksanaan program tersebut, oleh karena itu pada kegiatan ini kami melakukan evalusi melalui pengamatan dan Pre-Test dan Post-Test terhadap kader pembimbing anggota kelompok Bina Keluarga Balita (BKB) desa Lhambhuk serta melakukan wawancara mendalam terhadap anggota BKB. Dari hasil pengamatan, wawancara mendalam serta Pre-Test dan post test terhadap ibu-ibu pembimbing anggota BKB. Tampak bahwa terjadi peningkatan pengetahuan dan wawasan dari kader pembina Poktan, hal ini terlihat dari hasil Pre-test dan Post-Test. Semula nilai Pre-test rata-rata $65,5 \%$, setelah dilakukan edukasi dan 
dilaksanakan, maka nilai Post-Test meningkat menjadi $84,76 \%$. Dengan Peningkatan pemahaman tersebut, maka akan meningkatkan kemampuan mereka untuk memberikan edukasi kepada ibu-ibu yang mempunyai anak balita didesa sehingga masyarakat semakin paham bagaimana caranya melakukan pola asuh yang baik terhadap balita dan anak-anak.. Informasi ini berdasarkan hasil wawancara mendalam dengan ibu-ibu yang menjadi anggota BKB.

\section{KESIMPULAN}

Kegiatan pemberdayaan masyarakat dengan judul "Strategi Pengaktifan Kelompok Bina Keluarga Balita Di Kampung KB Lhambhuk Kecamatan Ulee Kareng Kota Banda Aceh" sangat bermanfaat bagi penduduk Desa Lhambuk. Hal ini bisa menjadi jalan keluar untuk penambah pengetahuan bagaimana pola asuh anak balita, kecukupan gizi serta membina dan membimbing anak balita menjadi anak yang berkualitas sebagai penerus kepemimpinan bangsa. Dengan adanya kegiatan pemberdayaan ini diharapkan Sebagai bahan masukan bagi para pengambil kebijakan agar mengoptimalkan peran para kader dalam rangka keberhasilan program Bina Keluarga Balita dimasa yang akan datang.

\section{DAFTAR RUJUKAN}

Badan Pusat Statistik Kota Banda Aceh, D. A. (2019). Kecamatan Ulee Kareng Dalam Angka 2019.

BKKBN. (2015). Petunjuk Teknis Kampung KB Tahun 2015. In Badan Kependudukan Dan Berencana Nasional (Vol. 53, Issue 9). http://ppid.kemendagri.go.id/storage/dokumen/30360000244_juknis_ka mpung_kb.pdf

Fu, N., Bosak, J., Flood, P. C., \& Ma, Q. (2019). Chinese and Irish professional service firms compared: Linking HPWS, organizational coordination, and firm performance. Journal of Business Research, 95(October 2017), 266-276. https://doi.org/10.1016/j.jbusres.2018.08.021

lqmy, L. O., Yantina, Y., \& Astari, N. (2019). Penyuluhan Pemilihan Alat Kontrasepsi Keluarga Berencana (KB) di Dusun Margorejo II Desa Kurungan Nyawa Kabupaten Pesawaran Tahun 2018. Jurnal Perak Malahayati, $1(1)$ 32-35. http://ejurnalmalahayati.ac.id/index.php/PERAKMALAHAYATI/article/vi ew/1518

Lantemona, G. H., Mantiri, M., \& Kasenda, V. (2017). Fungsi Koordinasi Camat Dalam Kegiatan Pemberdayaan Masyarakat Desa Di Kecamatan Modayag. Jurnal Eksekutif, 2(2), 1-10. https://ejournal.unsrat.ac.id/index.php/jurnaleksekutif/article/view/2071 7

Mardiyono. (2017). Kampung KB Sebagai Upaya Pemberdayaan Masyarakat/ Keluarga di Jawa Timur (Studi di Kota Malang dan Kabupaten Bondowoso). Jurnal Cakrawala, 11(2), 129-136. 
https://doi.org/10.32781/cakrawala.v11i2.13

Maryam. (2017). Gambaran Tingkat Pendidikan dan Pola Asuh Ibu pada Anak Usia Dini di Gampong Pante Gajah Kecamatan Matang Glumpang Dua Kabupaten Bireuen. GENDER EQUALITY: International Journal of Child and Gender, 3(2), 67-76. https://doi.org/10.22373/equality.v3i2.3443

Peraturan Kepala BKKBN No. 12 Tahun 2018 tentang pengelolaan Bina Keluarga Balita Holistik Integratif (BKB HI). (n.d.).

Putri, M. D., Sudarmiani, \& Aziz, U. K. (2020). Peran Kader Bina Keluarga Balita (BKB) dalam Kegiatan Bina Keluarga Balita (BKB) Taman Posyandu Desa Sedarat Kecamatan Balong Kabupaten Ponorogo. EQUILIBRIUM: Jurnal IImiah Ekonomi Dan Pembelajarannya, 8(1), 1. https://doi.org/10.25273/equilibrium.v8i1.5882

Sanda, J. P. (2020). Strategi Komunikasi Pemberdayaan Masyarakat Badan Kependudukan dan Keluarga Berencana Provinsi Sumatera Selatan di Kampung Layang-Layang Kecamatan Ilir Barat II Kota Palembang [Universitas

Sriwijaya]. https://repository.unsri.ac.id/34188/72/RAMA_70201_07031281621085 _0001057901_0005099303_01_Front_Ref.pdf

Setianingrum, S., Desmawati, L., \& Yusuf, A. (2017). Peranan Kader Bina Keluarga Balita dalam Optimalisasi Tumbuh Kembang Fisik Motorik Anak Usia Dini. Journal of Nonformal Education and Community Empowerment, 1(2), 137-145. https://doi.org/10.15294/pls.v1i2.13891

Yunas, N. S., \& Nailufar, F. D. (2019). COLLABORATIVE GOVERNANCE MELALUI PROGRAM KAMPUNG KB DI KABUPATEN JOMBANG. 5(2), $\quad$ 162-173. https://doi.org/Doi: https://doi.org/10.24198/cosmogov.v5i2.21814 